\title{
Optimal glucose and inoculum concentrations for production of bioactive molecules by Paenibacillus polymyxa RNC-D
}

\author{
${ }^{a}$ Nadja F. G. Serrano, ${ }^{b}$ Ligia Rodrigues, ${ }^{a}$ Carlos O. Hokka, ${ }^{a}$ Cristina P. Sousa, \\ ${ }^{b}$ José A. Teixeira, ${ }^{b}$ Solange I. Mussatto*
}

\begin{abstract}
${ }^{a}$ Post-Graduate Programme in Biotechnology, Federal University of Sao Carlos, Via Washington Luís, Km 235, Monjolinho, 13565-905, Sao Carlos/SP-Brazil

${ }^{\mathrm{b}}$ Institute for Biotechnology and Bioengineering (IBB), Centre of Biological Engineering, University of Minho, Campus Gualtar, 4710-057, Braga, Portugal
\end{abstract}

Received 1 March 2012; Revised 14 June 2012; Accepted 21 June 2012

\begin{abstract}
The production of antimicrobial metabolites by Paenibacillus polymyxa RNC-D was assessed. Two process variables, glucose and inoculum concentrations, were evaluated at different levels $(5-$ $40 \mathrm{~g} \mathrm{~L}^{-1}$, and at $\varphi_{\mathrm{r}}=2.5-5.0 \%$, respectively), and their effects on biomass formation, minimal inhibitory concentration (MIC) against Escherichia coli, and surface tension reduction (STR) were studied. When the fermentation process was carried out under non-optimised conditions, the biomass, MIC, and STR achieved the following values: $0.6 \mathrm{~g} \mathrm{~L}^{-1}, 1 \mathrm{~g} \mathrm{~L}^{-1}$, and $18.4 \mathrm{mN} \mathrm{m}^{-1}$, respectively. The optimum glucose $\left(16 \mathrm{~g} \mathrm{~L}^{-1}\right)$ and inoculum volume ratio $\left(\varphi_{\mathrm{r}}=5.0 \%\right)$ were defined in order to maximise the biomass formation, with a low value of MIC and high STR of extract. The experiments carried out under optimal conditions showed the following values for the dependent variables: biomass concentration $2.05 \mathrm{~g} \mathrm{~L}^{-1}$, MIC $31.2 \mu \mathrm{g} \mathrm{mL} \mathrm{m}^{-1}$, and STR $10.7 \mathrm{mN} \mathrm{m}^{-1}$, which represented improvement of $241.7 \%, 96.9 \%$, and $41.9 \%$ for the responses of biomass, MIC, and STR, respectively. This is the first recorded study on the optimisation of culture conditions for the production of antimicrobial metabolites of $P$. polymyxa RNC-D, and constitutes an important step in the development of strategies to modulate the production of antimicrobial molecules by this microorganism at elevated levels.
\end{abstract}

(c) 2012 Institute of Chemistry, Slovak Academy of Sciences

Keywords: antimicrobial metabolites, fermentation, minimal inhibitory concentration, Paenibacillus polymyxa, surface tension, optimisation

\section{Introduction}

Endophytes are regarded as an outstanding source of bioactive natural products because they occupy a unique biological environment: living plants (Strobel et al., 2004). Plant-associated microorganisms are subjected to constant metabolic and environmental interactions and, as a consequence, these organisms should produce even more secondary metabolites (Schulz, 2002). These molecules are characterised by their diverse chemical structures and may be of use due to the wide range of their bioactivity against pathogens. Paenibacillus polymyxa strains, for example, are recognised for their ability to produce antimicrobial peptides active against a broad range of microorganisms. One group of compounds, bioactive against both Gram-positive and Gram-negative bacteria, includes polymyxins (Katz \& Demain, 1977), jolipeptin (Ito \& Koyama, 1972a, 1972b), polypeptins (Sogn, 1976), gavaserin, and saltavalin (Pichard et al., 1995). Another group is comprised of molecules responsible for the bioactivity against Gram-positive

*Corresponding author, e-mail: solange@deb.uminho.pt, solangemussatto@hotmail.com 
bacteria and fungi, and includes gatavalin (Nakajima et al., 1972) and fusaridicins (Kajimura \& Kaneda, 1996, 1997).

Production of secondary metabolites by microorganisms varies qualitatively and quantitatively according to the strain and the cultivation conditions used (Lam et al., 1989; Wang et al., 2010). There are many factors potentially affecting the microbial metabolic processes, including the substrate and its concentration, inoculum concentration, medium composition, supply of air, temperature, $\mathrm{pH}$, and others. These conditions vary from species to species of microorganisms; as a consequence, it is important to know the environmental conditions of the microorganisms for maximum production of the desired metabolite (Gogoi et al., 2008; Adinarayana et al., 2003). The initial substrate and inoculum concentrations are two of the most important factors affecting the product formation by microorganisms, which is why they have been evaluated in many studies. However, it is of considerable interest to evaluate the simultaneous effect of the initial substrate and inoculum concentrations so as to avoid the use of a low substrate concentration per cell, which would yield low product formation, and also to avoid the use of an elevated substrate concentration per cell, which might lead to inhibition of the microbial metabolism.

The selection of the best operating conditions through factorial design and response surface methodology is a practice commonly employed in biotechnological processes, since this methodology permits the study of the effects of several factors influencing the responses by carrying out a limited number of experiments. Several works report on the use of statistical tools for the optimisation of fermentation conditions, such as initial substrate and inoculum concentrations, $\mathrm{pH}$, temperature, and aeration, among others (Santos et al., 2005; Mussatto \& Roberto, 2008; Shen et al., 2005)

The present paper is the first study on the optimisation of the culture conditions for the production of antimicrobial metabolites by Paenibacillus polymyxa RNC-D. Consequently, taking the above reasons into consideration, it focused on evaluating the effect of two process variables, namely the glucose and inoculum concentrations, on biomass formation, surface tension reduction, and the antimicrobial activity of the extract obtained from the fermentation cultures of endophytic P. polymyxa RNC-D.

\section{Experimental}

\section{Bacterial strains and culture media}

The endophytic bacterium Paenibacillus polymyxa RNC-D was isolated from leaves of Prunus spp., a Brazilian tropical savannah plant (Ratti et al., 2008). $P$. polymyxa RNC-D was grown in a YPM (yeast extract peptone agar medium) composed of: glucose (20 $\left.\mathrm{g} \mathrm{L} \mathrm{L}^{-1}\right)$, yeast extract $\left(11.25 \mathrm{~g} \mathrm{~L}^{-1}\right)$, peptone (11.25 $\left.\mathrm{g} \mathrm{L}^{-1}\right)$, malt extract $\left(20 \mathrm{~g} \mathrm{~L}^{-1}\right)$, and agar $\left(15 \mathrm{~g} \mathrm{~L}^{-1}\right)$. The $\mathrm{pH}$ of this medium was adjusted to 7.0 by adding a $5 \mathrm{M} \mathrm{NaOH}$ solution. For preparation of the YPM, all the components were sterilised in an autoclave at $121^{\circ} \mathrm{C}$ for $15 \mathrm{~min}$, except for the glucose solution that was sterilised in an autoclave at $112{ }^{\circ} \mathrm{C}$ for $15 \mathrm{~min}$, and aseptically mixed with the other components of the medium. For long storage periods, the bacterium was cultivated in YPM broth at $30^{\circ} \mathrm{C}$ for $16 \mathrm{~h}$, and then kept frozen in glycerol $\left(\varphi_{\mathrm{r}}=15 \%\right.$, $\left.t=-80^{\circ} \mathrm{C}\right)$. The Gram-negative indicator Escherichia coli ATCC 25922 was cultivated in Trypticase soy agar (TSA, Himedia, JMGS, Portugal) at $37^{\circ} \mathrm{C}$, and kept in slant tubes at $4^{\circ} \mathrm{C}$. Stock cultures of this microorganism were refreshed every three weeks. TSA was sterilised by autoclaving at $121^{\circ} \mathrm{C}$ for $15 \mathrm{~min}$.

\section{Inoculum and fermentation conditions}

An aliquot $(50 \mu \mathrm{L})$ of stock culture of $P$. polymyxa RNC-D was spread over a Petri dish containing YPM agar and maintained at $30^{\circ} \mathrm{C}$ for $48 \mathrm{~h}$. The inoculum was then prepared by transferring a single colony from the Petri dish into a 250-mL Erlenmeyer flask containing $100 \mathrm{~mL}$ of YPM broth. The flask was incubated in an orbital shaker at $30^{\circ} \mathrm{C}$ and $180 \mathrm{~min}^{-1}$ for $16 \mathrm{~h}$. The cells were recovered by centrifugation $(18895 \mathrm{~g}, 15 \mathrm{~min})$ and washed twice in sterile water. Subsequently, the inoculum was prepared by adjusting the optical density $(600 \mathrm{~nm})$ to 1.0 and a volume ratio in the range of $\varphi_{\mathrm{r}}=2.5-5.0 \%$ was transferred to the fermentation media. Batch fermentations were carried out in 500-mL Erlenmeyer flasks containing $200 \mathrm{~mL}$ of YPM broth (pH 7.0) with glucose concentrations varying from $5 \mathrm{~g} \mathrm{~L}^{-1}$ to $40 \mathrm{~g} \mathrm{~L}^{-1}$. The $\mathrm{pH}$ was not monitored in the course of the fermentation. The flasks were incubated at $30^{\circ} \mathrm{C}, 180 \mathrm{~min}^{-1}$, for $96 \mathrm{~h}$. After this time, the fermented broth was centrifuged (18895 $\mathrm{g}, 15 \mathrm{~min}$ ) and the pellet thus obtained was used to determine the biomass formation. The extract was filtered through an $0.22 \mu \mathrm{m}$ membrane filter and further used to measure the surface tension and to assess the antimicrobial activity.

\section{Analytical methods}

The biomass concentration $\left(\mathrm{g} \mathrm{L}^{-1}\right)$ was determined by measuring the absorbance of the fermented medium, which were then correlated via a calibration curve (dry mass $\times$ optical density). A volume of $100 \mathrm{~mL}$ of 96 -h culture broth was centrifuged (18895g, $15 \mathrm{~min}$ ) and the pellet was washed twice in distilled water. Next, the cells were re-suspended in $100 \mathrm{~mL}$ of distilled water and this cellular suspension was diluted 10-, 20-, 30-, 40-, 50-, 100-, 200-, 500-, and 1000fold. The optical density at $600 \mathrm{~nm}$ of the diluted so- 
Table 1. Experimental matrix with real and coded values of independent variables used in glucose fermentation by Paenibacillus polymyxa RNC-D, and results obtained for responses of biomass formation, MIC against E. coli, and surface tension reduction $(\mathrm{STR})$

\begin{tabular}{|c|c|c|c|c|c|}
\hline \multirow{3}{*}{ Assay } & \multicolumn{2}{|c|}{$\begin{array}{l}\text { Independent variables }{ }^{a} \\
\text { Real and (coded) values }\end{array}$} & \multicolumn{3}{|c|}{ Responses (dependent variables) } \\
\hline & $x_{1}$ & $x_{2}$ & Biomass & $\mathrm{MIC}$ & STR \\
\hline & $\mathrm{g} \mathrm{L}^{-1}$ & $\%$ & $\mathrm{~g} \mathrm{~L}^{-1}$ & $\mu \mathrm{g} \mathrm{mL}-1$ & $\mathrm{mN} \mathrm{m}^{-1}$ \\
\hline 1 & $5(-1)$ & $2.5(-1)$ & 0.60 & 1000.0 & 18.4 \\
\hline 2 & $40(+1)$ & $2.5(-1)$ & 2.13 & 15.6 & 14.84 \\
\hline 3 & $5(-1)$ & $5.0(+1)$ & 0.76 & 250.0 & 20.0 \\
\hline 4 & $40(+1)$ & $5.0(+1)$ & 4.11 & 15.6 & 11.5 \\
\hline 5 & $40(+1)$ & $3.75(0)$ & 3.09 & 31.25 & 11.6 \\
\hline 6 & $5(-1)$ & $3.75(0)$ & 0.69 & 500.0 & 16.25 \\
\hline 7 & $22.5(0)$ & $5.0(+1)$ & 3.33 & 62.5 & 14.1 \\
\hline 8 & $22.5(0)$ & $2.5(-1)$ & 2.90 & 62.5 & 10.5 \\
\hline 9 & $22.5(0)$ & $3.75(0)$ & 3.05 & 31.25 & 9.8 \\
\hline 10 & $22.5(0)$ & $3.75(0)$ & 3.13 & 62.5 & 9.8 \\
\hline 11 & $22.5(0)$ & $3.75(0)$ & 3.01 & 62.5 & 10.2 \\
\hline
\end{tabular}

a) $x_{1}=$ glucose concentration; $x_{2}=$ inoculum volume fraction $\left(\varphi_{\mathrm{r}}\right)$.

lutions was measured. Meanwhile, known volumes of the cells suspension prepared in $100 \mathrm{~mL}$ of distilled water were dried at $105^{\circ} \mathrm{C}$ until they achieved a constant mass. The biomass concentration in each diluted sample was then correlated with the respective value of absorbance. A calibration curve was established for each glucose concentration used in the experiments (OD - optical density; B - biomass concentration), namely $5 \mathrm{~g} \mathrm{~L}^{-1}$ (Eq. (1)), $22.5 \mathrm{~g} \mathrm{~L}^{-1}$ (Eq. (2)), and $40 \mathrm{~g} \mathrm{~L}^{-1}$ (Eq. (3)), and elevated values of the coefficient of determination $\left(R^{2}\right)$ were obtained.

$$
\begin{aligned}
& \mathrm{OD}=0.0363 B+0.0273 ; R^{2}=0.9862 \\
& \mathrm{OD}=0.0237 B+0.0259 ; R^{2}=0.9937 \\
& \mathrm{OD}=0.0436 B+0.0339 ; R^{2}=0.9947
\end{aligned}
$$

The surface tension of extracts produced by $P$. polymyxa RNC-D was determined by the ring method (Rodrigues et al., 2006) using a KRUSS tensiometer (Kruss, Dias de Sousa, Portugal) equipped with a $1.9 \mathrm{~cm}$ De Noüy platinum ring (Kruss, Dias de Sousa, Portugal) at ambient temperature. The surface tension reduction (STR) in the extracts, as compared with the medium, was expressed in $\mathrm{mN} \mathrm{m}^{-1}$.

The antimicrobial activity of the extracts was quantified by the micro-dilution technique (National Committee for Clinical Laboratory Standards, 2002) and the minimal inhibitory concentration (MIC) was expressed in $\mu \mathrm{g} \mathrm{mL}^{-1}$. Gram-negative indicator strain was cultivated for $16 \mathrm{~h}$ in Tryptic soy broth (TSB) at $37^{\circ} \mathrm{C}$ and $120 \mathrm{~min}^{-1}$, being the cells collected by centrifugation $(9055 \mathrm{~g}, 5 \mathrm{~min})$. The bacterial biomass was re-suspended in Mueller-Hinton broth (MHB, Oxoid, JMGS, Portugal) and the inoculum adjusted to $10^{6}$
CFU per mL. A volume of $100 \mu \mathrm{L}$ of the bacterial suspension was displayed in each well of a 96 -well plate. Similarly, the extracts were twice serially diluted using MHB and $100 \mu \mathrm{L}$ was added to the wells, in triplicate. Positive and negative controls were made by the following procedures, respectively: $100 \mu \mathrm{L}$ of YPM plus $100 \mu \mathrm{L}$ of bacterial inoculum (MHB) and $100 \mu \mathrm{L}$ of YPM plus $100 \mu \mathrm{L}$ of MHB. The 96-well microplates were incubated at $37^{\circ} \mathrm{C}, 120 \mathrm{~min}^{-1}$ for $24 \mathrm{~h}$. MIC is defined as the lowest extract concentration in which indicator microorganisms did not demonstrate visible growth.

\section{Experimental design}

The influence of the variables: glucose concentration $\left(x_{1}\right)$ and inoculum concentration $\left(x_{2}\right)$ on the production of antimicrobial metabolites by $P$. polymyxa RNC-D was evaluated through a $2^{2}$ central composite design with three coded levels, leading to eleven sets of experiments. For statistical analysis, the variables were coded according to Eq. (4), where each independent variable is represented by $x_{i}$ (coded value), $X_{i}$ (real value), $X_{0}$ (real value at the centre point), and $\Delta X_{i}$ (step change value). The range and levels of the variables, which were selected based on data from the literature, are given in Table 1.

$$
x_{i}=\frac{\left(X_{i}-X_{0}\right)}{\Delta X_{i}}
$$

Three assays in the centre point were carried out to estimate the experimental error needed for analysis of the variance, as well as to examine the presence of curvature in the response surfaces and to investigate the suitability of the proposed models. The biomass 
Table 2. Analysis of variance for effects of glucose and inoculum concentrations on responses of biomass formation, MIC against E. coli and surface tension reduction (STR), during glucose fermentation by Paenibacillus polymyxa RNC-D

\begin{tabular}{|c|c|c|c|c|c|c|c|c|c|c|c|c|}
\hline \multirow{2}{*}{ Source of variation } & \multicolumn{4}{|c|}{ Biomass } & \multicolumn{4}{|c|}{$\mathrm{MIC}$} & \multicolumn{4}{|c|}{ STR } \\
\hline & SS & $\mathrm{DF}$ & $F$-value & $p$-value & SS & $\mathrm{DF}$ & $F$-value & $p$-value & SS & $\mathrm{DF}$ & $F$-value & $p$-value \\
\hline (1) Glucose (L) & 8.84 & 1 & 297.65 & $0.000^{a}$ & 474637.5 & 1 & 42.87 & $0.001^{a}$ & 46.54 & 1 & 31.41 & $0.003^{a}$ \\
\hline Glucose (Q) & 3.63 & 1 & 122.30 & $0.000^{a}$ & 142097.4 & 1 & 12.84 & $0.016^{b}$ & 39.24 & 1 & 26.48 & $0.004^{a}$ \\
\hline (2) Inoculum (L) & 1.10 & 1 & 37.04 & $0.002^{a}$ & 93750.0 & 1 & 8.47 & $0.033^{b}$ & 0.58 & 1 & 0.39 & 0.560 \\
\hline Inoculum (Q) & 0.00 & 1 & 0.10 & 0.769 & 2878.9 & 1 & 0.26 & 0.632 & 13.52 & 1 & 9.13 & $0.029^{b}$ \\
\hline (1) L by (2) L & 0.82 & 1 & 27.61 & $0.003^{a}$ & 140625.0 & 1 & 12.70 & $0.016^{b}$ & 6.10 & 1 & 4.12 & 0.098 \\
\hline Error & 0.15 & 5 & - & - & 55357.3 & 5 & - & - & 7.41 & 5 & - & - \\
\hline Total & 14.76 & 10 & - & - & 932057.6 & 10 & - & - & 130.65 & 10 & - & - \\
\hline
\end{tabular}

a) Significant at $99 \%$ confidence level; $b$ ) significant at $95 \%$ confidence level. SS - sum of squares; DF - degrees of freedom; L linear term; Q - quadratic term. $R^{2}=0.99$ for biomass, and 0.94 for MIC and STR.

formation, MIC against E. coli, and the surface tension reduction (STR) were taken as dependent variables or responses of the design experiments. Analysis of the data by response surface methodology made it possible to define equations to allow calculation of the maximum values to be achieved for each response, individually. The quadratic models for predicting the optimal point to each response were expressed by Eq. (5), where $y_{i}$ represents the response variable, $b_{0}$ is the interception coefficient, $b_{1}$ and $b_{2}$ the linear terms, $b_{11}$ and $b_{22}$ the quadratic terms, and $x_{1}$ and $x_{2}$ represent the variables studied.

$$
\hat{y}_{i}=b_{0}+b_{1} x_{1}+b_{2} x_{2}+b_{12} x_{1} x_{2}+b_{11} x_{1}^{2}+b_{22} x_{2}^{2}
$$

Design expert version 5.0 and Statistica version 5.0 were the software used for regression and graphical analyses of the data. The statistical significance of the regression coefficients was determined by Student's $t$ test. The second-order model equations were determined by Fischer's test, and the proportion of variance explained by the models obtained was given by the multiple coefficient of determination $R^{2}$. The optimum values of the variables were obtained by graphical and numerical analyses, based on the criterion of desirability. At a later stage, a condition capable of simultaneously maximising the three responses was established by graphical optimisation, and fermentation experiments were performed in triplicate to validate the model and to calculate the standard error.

\section{Results and discussion}

A $2^{2}$ central composite design with three repetitions at the central point was employed to study the effect of glucose and inoculum concentrations on the production of antimicrobial metabolites produced by $P$. polymyxa RNC-D. The experimental matrix with the real and coded levels of the variables, as well as the results of biomass formation, MIC against E. coli and STR, is shown in Table 1. As may be seen, the values of the responses varied significantly depending on the glucose and inoculum concentrations used in each experiment. Biomass formation, for example, had an almost 7 -fold increase under the experimental conditions applied. The MIC values also varied considerably from $15.6 \mu \mathrm{g} \mathrm{mL} \mathrm{m}^{-1}$ to $1000 \mu \mathrm{g} \mathrm{mL}{ }^{-1}$, while the maximum reduction in the surface tension of extract reached $20.0 \mathrm{mN} \mathrm{m}^{-1}$ (assay 3 ).

Analysis of variance of the data presented in Table 1 revealed significant effects $(p<0.05)$ of both variables, glucose and inoculum concentrations, in all the responses (Table 2). The initial glucose concentration was also shown to have a significant influence in the production of a novel antimicrobial peptide by Bacillus sp. fmbJ224 (Shen et al., 2005). According to this study, the optimal concentration of glucose was $8.13 \mathrm{~g} \mathrm{~L}^{-1}$, which in combination with other variables allowed the content of the peptide to increase from $1,304.21 \mu \mathrm{g} \mathrm{mL} \mathrm{mL}^{-1}$ to $1,487.58 \mu \mathrm{g} \mathrm{mL}^{-1}$, representing an improvement of $14.05 \%$. The data presented in this study plus those attained by Shen et al. (2005) confirmed, as stated previously, that the initial substrate and inoculum concentrations were parameters of significant influence on fermentation processes, as also reported by other authors (Adinarayana et al., 2003; Gogoi et al., 2008; Mussatto \& Roberto, 2008).

The statistical significance of the quadratic terms (Q) (Table 2) suggests that second-order polynomial equations are more suitable than first-order equations for describing the responses variations as a function of the glucose and inoculum variations. The parameters of the second-order models used to estimate the biomass, MIC and STR variations as a function of the variables variations were then obtained by multiple regression analysis. When possible, the variables or interaction terms not significant at $95 \%$ confidence level were excluded from the models. Mathematical models representing the biomass formation, MIC against $E$. coli, and STR in the experimental region considered in the present study, were expressed by Eqs. (6), (7), and (8), respectively, where the variables (glucose concentration, $x_{1}$; inoculum concentration, $\left.x_{2}\right)$ assumed their coded values. The models did not show lackof-fit and presented high coefficients of determination $\left(R^{2} \geq 0.89\right)$, explaining more than $89.0 \%$ of the vari- 

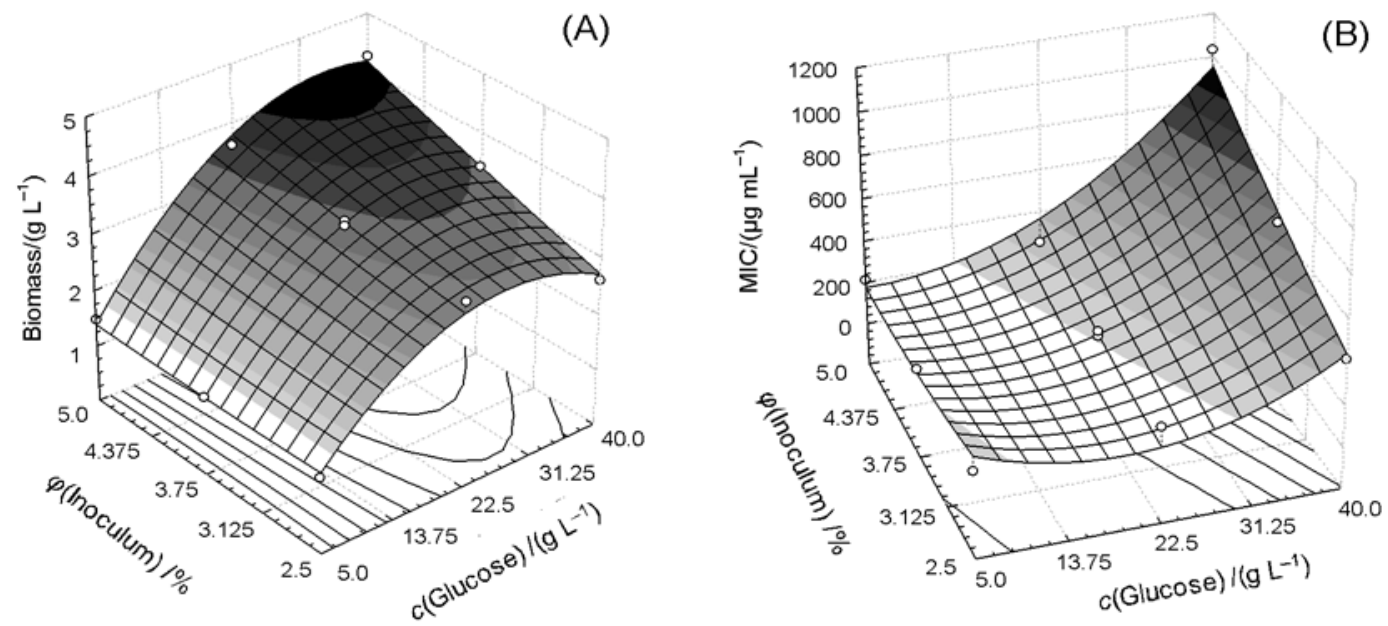

(B)

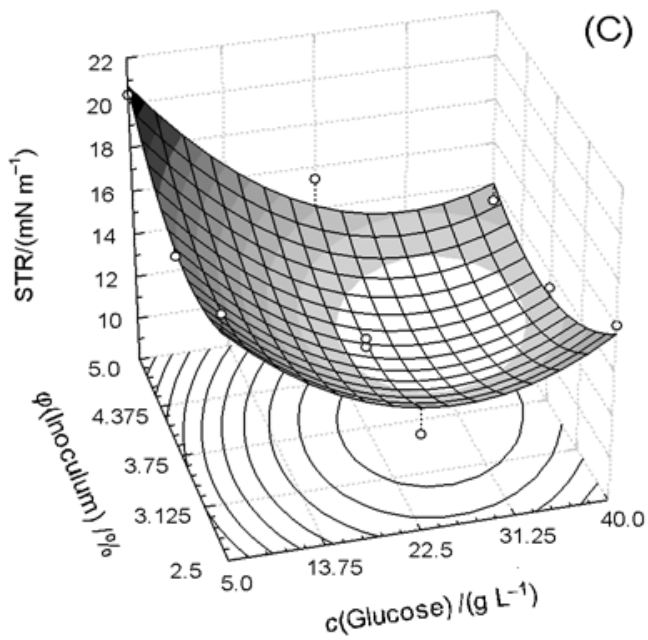

Fig. 1. Response surface described by models representing biomass formation (A), MIC against E. coli (B), and surface tension reduction - STR (C) in glucose fermentation by Paenibacillus polymyxa RNC-D.

ability in the responses. These models are very useful for rapid prediction of the maximum value to be obtained for each response when varying the glucose and inoculum concentrations in the range of values studied here.

$$
\begin{gathered}
\text { Biomass }\left(\mathrm{g} \mathrm{L}^{-1}\right)=3.08+1.21 x_{1}-1.19 x_{1}^{2}+ \\
+0.43 x_{2}+0.45 x_{1} x_{2} ; R^{2}=0.99 \\
\text { MIC }\left(\mu \mathrm{g} \mathrm{mL}^{-1}\right)=56.25-281.26 x_{1}+ \\
+245.83 x_{1}^{2}-125 x_{2}+187.5 x_{1} x_{2} ; R^{2}=0.94
\end{gathered}
$$

$$
\operatorname{STR}\left(\mathrm{mN} \mathrm{m}^{-1}\right)=9.96-2.79 x_{1}+3.94 x_{1}^{2}+2.31 x_{2}^{2} \text {; }
$$$$
R^{2}=0.89
$$

Raza et al. (2010) also used the RSM to evaluate the effect of metal ions $\mathrm{Ca}^{2+}, \mathrm{Ni}^{2+}, \mathrm{Mn}^{2+}, \mathrm{Cu}^{2+}$ on the production of antifungal compounds (fusaricidns A, B, C, and D) by P. polymyxa SQR-21. The values of responses diameter of inhibition zone $(\mathrm{mm})$ and growth (OD at $600 \mathrm{~nm}$ ) were recorded for each experimental condition used in this study and a high degree of correlation between the observed and predicted data of the inhibition zone $\left(R^{2}=0.74\right)$ and growth $\left(R^{2}=0.71\right)$ was obtained by these authors. In the present study, higher values of the coefficients of determination were achieved, such as 0.99 for biomass, 0.94 for MIC, and 0.89 for STR. These elevated values represent a better fit for the regression equations to the experimental results.

The three-dimensional response surfaces described by the model equations are represented in Fig. 1. These surfaces clearly show the existence of regions where the response values are maximised or minimised, presenting the relationships between variables and responses. Biomass formation, for example (Fig. 1A), is maximised when using the highest inoculum level and glucose concentration varying between $22.5 \mathrm{~g} \mathrm{~L}^{-1}$ and $40 \mathrm{~g} \mathrm{~L}^{-1}$ (dark region of the graph). Similar values of glucose and inoculum concentration 


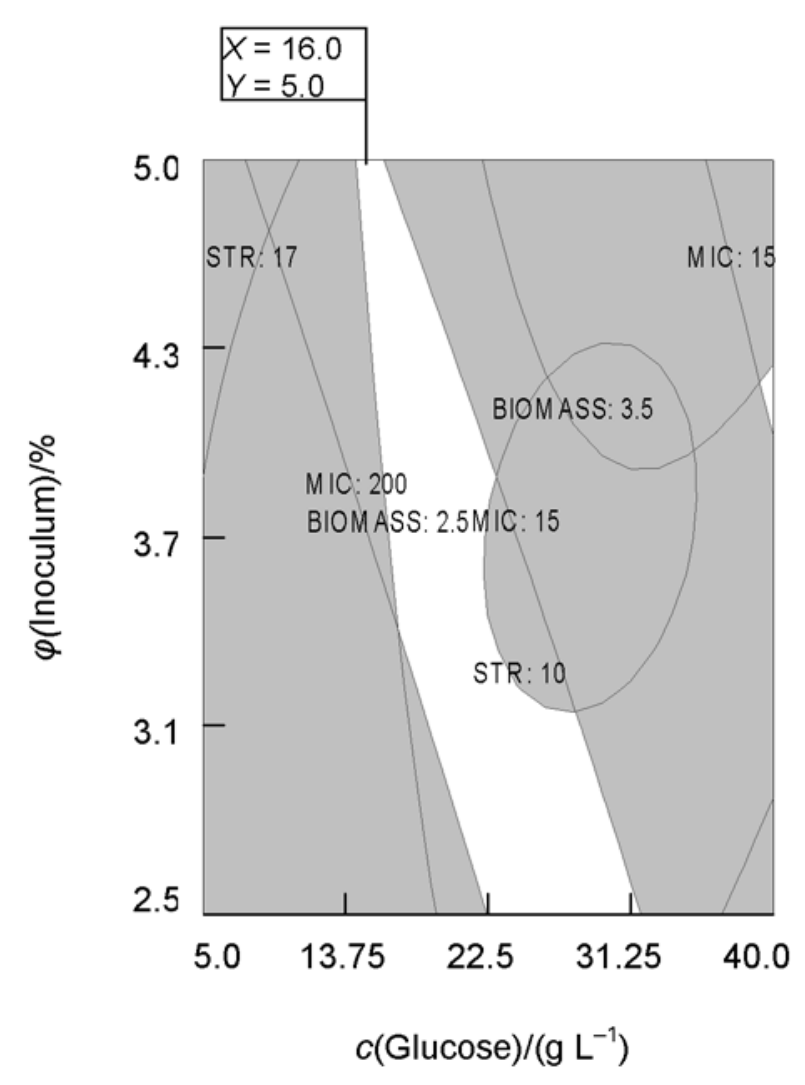

Fig. 2. Optimum region by overlay plots of three responses evaluated (biomass formation, MIC against E. coli, and surface tension reduction - STR) as a function of glucose and inoculum concentrations.

were not best suited for obtaining the lowest MIC values (white region in Fig. 1B) or the highest STR (dark region in Fig. 1C). Therefore, a graphical optimisation based on the three proposed models was performed to find out a point or a region where the results of biomass and STR could be as high as possible, whereas the MIC values could be as low as possible.

The graphical optimisation method essentially consisted of overlaying the curves of all the models according to the criteria imposed. In the present study, the criteria adopted were: biomass formation between $2.5 \mathrm{~g} \mathrm{~L}^{-1}$ and $3.5 \mathrm{~g} \mathrm{~L}^{-1}$ (a), MIC values between $15 \mu \mathrm{g} \mathrm{mL}^{-1}$ and $200 \mu \mathrm{g} \mathrm{mL} \mathrm{m}^{-1}(\mathrm{~b})$, and STR between $10 \mathrm{mN} \mathrm{m}^{-1}$ and $17 \mathrm{mN} \mathrm{m}^{-1}$ (c). The overlaying plot attained (Fig. 2) shows an area where all the imposed criteria were satisfied (white region). A point was assigned in this area as optimum point (marked by the square) which corresponded to an initial glucose concentration of $16 \mathrm{~g} \mathrm{~L}^{-1}$ and inoculum of $\varphi_{\mathrm{r}}=5 \%$. Under these conditions, the model predicts a biomass of $2.76 \mathrm{~g} \mathrm{~L}^{-1}$, MIC of $15.80 \mu \mathrm{g} \mathrm{mL}^{-1}$ and STR of 14.58 $\mathrm{mN} \mathrm{m}^{-1}$. Assays for validation of this model were then performed under the established operating conditions and values were found of $2.05 \mathrm{~g} \mathrm{~L}^{-1}, 31.2 \mu \mathrm{g} \mathrm{mL}{ }^{-1}$, and $10.7 \mathrm{mN} \mathrm{m}^{-1}$ for biomass, MIC, and STR, respectively. These values are in agreement with the criteria adopted for optimisation and confirm the validity of the model.

A similar initial substrate concentration (12.3 $\mathrm{g} \mathrm{L}^{-1}$ ) was optimised for the production of antifungal active substances by $P$. polymyxa $\mathrm{Cp}-\mathrm{S} 316$ from lactose (Wang \& Liu, 2008). In that study, preliminary experiments revealed that the carbon source lactose was presumed to affect antifungal active substances production by $P$. polymyxa $\mathrm{Cp}-\mathrm{S} 316$. This strain is capable of producing antifungal compounds, polymyxin $\mathrm{E}$, and at least three novel peptide antibiotics when cultivated in a medium with potato, lactose, beef extract, $\mathrm{NH}_{4} \mathrm{SO}_{4}, \mathrm{MgSO}_{4}, \mathrm{KH}_{2} \mathrm{PO}_{4}$. By applying an inoculum of $\varphi_{\mathrm{r}}=2 \%$ and a lactose concentration of $12.3 \mathrm{~g} \mathrm{~L}^{-1}$, it was possible to obtain $4.69 \mu \mathrm{g} \mathrm{mL}-1$ of antifungal compounds, representing a 3.05 -fold increase when compared with the production obtained in the basal medium. This initial concentration of carbon source is close to that $\left(16 \mathrm{~g} \mathrm{~L}^{-1}\right)$ predicted and validated in the present study. The adjustment in the concentration of carbon source had an important role in activation of the secondary metabolism of P. polymyxa $\mathrm{Cp}-\mathrm{S} 316$, resulting in increased production of antifungal compounds. The same result was observed in this study, in which the percentage of improvement for MIC against E. coli was $96.9 \%$.

Establishment of the optimum fermentation condition constitutes an important step in the development of strategies to modulate the production of antimicrobial molecules by $P$. polymyxa RNC-D at elevated levels. Data acquired from a previous study revealed that $P$. polymyxa RNC-D produced three antimicrobial molecules when cultivated in YPM medium: fusaricidin A (active against Gram-positive bacteria and fungi), polymyxin E, and a novel antimicrobial peptide (AMP) - both active against Gram-negative bacteria. The AMP is a short depsipeptide with five residues of amino acids, and which includes hydroxyproline in its structure.

\section{Conclusions}

Glucose and inoculum concentrations are variables with substantial influence on the production of antimicrobial metabolites by $P$. polymyxa RNC-D. By using the experimental factorial design method and response surface methodology followed by graphical optimisation, it was possible to determine the optimum operating condition in order to achieve the biomass and STR as high as possible, and the MIC values as low as possible. The validity of the proposed model was verified and confirmed. When the fermentation process was carried out under non-optimised conditions, the values of biomass, MIC, and STR were $0.6 \mathrm{~g} \mathrm{~L}^{-1}, 1 \mathrm{~g} \mathrm{~L}^{-1}$, and $18.4 \mathrm{mN} \mathrm{m}^{-1}$, respectively. However, when the experiments were performed under optimised conditions, these values were correspondent to $2.05 \mathrm{~g} \mathrm{~L}^{-1}$, $31.2 \mu \mathrm{g} \mathrm{mL}^{-1}$, and $10.7 \mathrm{mN} \mathrm{m}^{-1}$, respectively, repre- 
senting a percentage of improvement for each target response of $241.7 \%, 96.9 \%$, and $41.9 \%$. This study thus constitutes an important step in the development of strategies to modulate the production of antimicrobial molecules by $P$. polymyxa RNC-D at elevated levels. The next stage of this research will spotlight enhancement of the production of the novel antimicrobial peptide by the endophytic strain.

Acknowledgements. The authors wish to express their gratitude to the ISAC Project - Erasmus Mundus External Cooperation Windows Programme (2008-3628/001-001).

\section{References}

Adinarayana, K., Prabhakar, T., Srinivasulu, V., Anitha Rao, M., Jhansi Lakshmi, P., \& Ellaiah, P. (2003). Optimization of process parameters for cephalosporin $\mathrm{C}$ production under solid state fermentation from Acremonium chrysogenum. Process Biochemistry, 39, 171-177. DOI: 10.1016/s00329592(03)00049-9.

Gogoi, D. K., Mazumder, S., Saikia, R., \& Bora, T. C. (2008). Impact of submerged culture conditions on growth and bioactive metabolite produced by endophyte Hypocrea spp. NSF08 isolated from Dillenia indica Linn. in North-East India. Journal de Mycologie Médicale/Journal of Medical Mycology, 18, 1-9. DOI: 10.1016/j.mycmed.2007.10.006.

Ito, M., \& Koyama, Y. (1972a). Jolipeptin, a new peptide antibiotic. I. Isolation, physico-chemical and biological characteristics. The Journal of Antibiotics, 25, 304-308. DOI: 10.7164/antibiotics.25.304.

Ito, M., \& Koyama, Y. (1972b). Jolipeptin, a new peptide antibiotic. II. The mode of action of jolipeptin. The Journal of Antibiotics, 25, 309-314. DOI: 10.7164/antibiotics.25.309.

Kajimura, Y., \& Kaneda, M. (1996). Fusaricidin A, a new depsipeptide antibiotic produced by Bacillus polymyxa KT-8. Taxonomy, fermentation, isolation, structure elucidation and biological activity. The Journal of Antibiotics, 49, 129-135. DOI: 10.7164 /antibiotics.49.129.

Kajimura, Y., \& Kaneda, M. (1997). Fusaricidins B, C, and D, new depsipeptide antibiotics produced by Bacillus polymyxa KT-8: Isolation, structure elucidation and biological activity. The Journal of Antibiotics, 50, 220-228. DOI: 10.7164/antibiotics.50.220.

Katz, E., \& Demain, A. L. (1977). The peptide antibiotics of Bacillus: chemistry, biogenesis, and possible functions. Bacteriology Reviews, 41, 449-474.

Lam, K. S., Mattei, J., \& Forenza, S. (1989). Carbon catabolite regulation of rebeccamycin production in Saccharothrix aerocolonigenes. Journal of Industrial Microbiology 86 Biotechnology, 4, 105-108. DOI: 10.1007/bf01569794.

Mussatto, S. I., \& Roberto, I. C. (2008). Establishment of the optimum initial xylose concentration and nutritional supplementation of brewer's spent grain hydrolysate for xylitol production by Candida guilliermondii. Process Biochemistry, 43, 540-546. DOI: 10.1016/j.procbio.2008.01.013.
Nakajima, N., Chihara, S., \& Koyama, Y. (1972). A new antibiotic, gatavalin. I. Isolation and characterization. The Journal of Antibiotics, 25, 243-247. DOI: 10.7164/antibiotics.25.243.

National Committee for Clinical Laboratory Standards (2002). Performance standards for antimicrobial susceptibility testing (12th Informational supplement). Wayne, PA, USA: Clinical and Laboratory Standards Institute. (M100-S12)

Pichard, B., Larue, J. P., \& Thouvenot, D. (1995). Gavaserin and saltavalin, new peptide antibiotics produced by Bacillus polymyxa. FEMS Microbiology Letters, 133, 215-218. DOI: 10.1111/j.1574-6968.1995.tb07887.x.

Ratti, R. P., Serrano, N. F. G., Hokka, C. O., \& Sousa, C. P. (2008). Antagonistic properties of some microorganisms isolated from Brazilian tropical savannah plants against Staphylococcus coagulase-positive strain. Journal of Venomous Animals and Toxins Including Tropical Diseases, 14, 294-302. DOI: $10.1590 / \mathrm{s} 1678-91992008000200007$.

Raza, W., Wu, H. S., \& Shen, Q. R. (2010). Use of response surface methodology to evaluate the effect of metal ions $\left(\mathrm{Ca}^{2+}, \mathrm{Ni}^{2+}, \mathrm{Mn}^{2+}, \mathrm{Cu}^{2+}\right)$ on production of antifungal compounds by Paenibacillus polymyxa. Bioresource Technology, 101, 1904-1912. DOI: 10.1016/j.biortech.2009.10.029.

Rodrigues, L. R., Teixeira, J. A., van der Mei, H. C., \& Oliveira, R. (2006). Isolation and partial characterization of a biosurfactant produced by Streptococcus thermophilus A. Colloids and Surfaces B: Biointerfaces, 53, 105-112. DOI: 10.1016/j.colsurfb.2006.08.009.

Santos, J. C., Mussatto, S. I., Cunha, M. A. A., \& Silva, S. S. (2005). Variables that affect xylitol production from sugarcane bagasse hydrolysate in a zeolite fluidized bed reactor. Biotechnology Progress, 21, 1639-1643. DOI: 10.1021/bp05 0219n.

Schulz, B., Boyle, C., Draeger, S., Römmert, A. K., \& Krohn, K. (2002). Endophytic fungi: a source of novel biologically active secondary metabolites. Mycological Research, 106, 996-1004. DOI: $10.1017 / \mathrm{s} 0953756202006342$.

Shen, J., Lu, Z. X., Bie, X. M., Lü, F. X., \& Huang, X. Q. (2005). Media optimization for the novel antimicrobial peptide by Bacillus sp. fmbJ224. Chinese Journal of Biotechnology, 21, 609-614. (in Chinese)

Sogn, J. A. (1976). Structure of the peptide antibiotic polypeptin. Journal of Medicinal Chemistry, 19, 1228-1231. DOI: 10.1021/jm00232a012.

Strobel, G., Daisy, B., Castillo, U., \& Harper, J. (2004). Natural products from endophytic microorganisms. Journal of Natural Products, 67, 257-268. DOI: 10.1021/np030397v.

Wang, Z. W., \& Liu, X. L. (2008). Medium optimization for antifungal active substances production from a newly isolated Paenibacillus sp. using response surface methodology. Bioresource Technology, 99, 8245-8251. DOI: 10.1016/j.biortech.2008.03.039.

Wang, X., Huang, L., Kang, Z., Buchenauer, H., \& Gao, X. (2010). Optimization of the fermentation process of Actinomycete strain Hhs. $015^{T}$. Journal of Biomedicine and Biotechnology, 2010, 141876. DOI: 10.1155/2010/141876. 